\title{
The methodological strategy for the continuous text analysis in the teaching of philological sciences
}

\author{
N.V. Dronyakina ${ }^{1 *}$, and E.R. Chemezova ${ }^{2}$ \\ ${ }^{1}$ V.I. Vernadsky Crimean Federal University, Simferopol, Russia \\ ${ }^{2}$ V.I. Vernadsky Crimean Federal University, Simferopol, Russia
}

\begin{abstract}
The article considers the need for the elaboration of the modern strategy for text interpretation by prospective philologists. This issue caused by the new tendencies in higher professional education aimed at developing new theoretical approaches to updating the content and methods of pedagogical activity. In the focus area of modern educational process are methods of enriching the students' culturological background, since the scope of tasks the institutions of higher education for the humanities set today incorporates the training of qualified graduates having profound theoretical learning in philosophy, cultural studies, and art. The very hermeneutical approach contributes to effective training of prospective philologists to decode the author's message having its deeplying roots in the textual space. The continuous text analysis is developed for the students of different educational and academic background but able to interpret the text under study. Such an approach to the study of the textual content and composition may presuppose the students' reference to lexicographic resources of culture, history, symbols, philosophy, etc. We consider this methodological tool to be the most effective and promising in training the prospective philologists able to perceive and interpret continuously any text in class or independently.
\end{abstract}

\section{A problem statement}

Modern philological science requires the latest scientific researches and technologies that can be used in the preparation of a specialist in any direction of training. Text analysis is one of the fundamental elements in the teaching of philological disciplines. In the Order of the Government of the Russian Federation of December 31, 2020 N 3684-p "On the approval of the Program of fundamental scientific research in the Russian Federation for the long term (2021-2030)", the need to develop new theoretical approaches to updating the content and methods of pedagogical activity is stated, which necessitates consideration the issue of text analysis and its implementation as a teaching strategy. In working with modern teaching strategies, many researchers consider text analysis as part of the technology of building discussion in the classroom [1] and written analysis [2].

* Corresponding author: prof-ped.gpa@mail.ru 
The modern multimodal concept of teaching the language and literature, which determines the most effective directional vector of modern philological education, emphasizes the work with the text mainly to the literary text as the main means of entering the linguistic personality into the culture.

Literary and linguistic analysis in the learning process and its place in specialist training is a frequent aspect studied by many scholars $[3,4]$. Continuous analysis of the text in the educational process remains outside the pedagogical research of researchers, which leads to a lack of study of the issue and the application of this educational strategy in general.

Any text is dialogical and polylogical. This is a dialogue between the author and the conceptual sphere of culture, with the reader, etc. This is a "flashcard" of compressed, condensed, reduced cultural dialogues. The dialogue of the reader with the author, his cognitive essence, the conceptual sphere of culture is carried on in the process of perception and understanding of the literary text, i.e. in the process of reading. One of the most productive ways of such reading is the hermeneutical study of a literary text, which presupposes a comprehensive approach to the phenomena, essence and patterns of imagery, combining philology with other sciences in order to fulfill the most difficult priority task of modern education - the integration of the personality of the student into the system of national and world cultures.

Higher school represents various methods of text analysis, which requires monumental preparation, consistency of application and constancy for the development of the skill of such work with research material both in-class studies and during students' independent work.

\subsection{The objective of the work}

Based on the identified problem, we see the need for a new strategy in pedagogical science. Such a strategy will help to solve a number of issues related, first of all, to the qualitative analysis of the text, taking into consideration the different levels of theoretical and practical training of students.

This gave us a reason to build our own theoretical and practical research in such a way that, based on the theoretical material, we can present new practical data that can complement the pedagogical base. The theoretical basis of the research is the works of such Russian and foreign authors as L.N. Arbachakova, I.A. Nevskaya [5], J. Ruth-Gordon [6], C. Grandy [7], J. Szerszunowicz [8], R.L. Troxel [9], T. Wilson-Bates [10], A.K. Webster [11, 12].

The work of these researchers in the field of philology, pedagogy, sociology, philosophy, cultural studies, mythology and folklore, history formed the basis of this study and became a significant stage in the process of understanding the above-described issues. They made it possible to supplement the theoretical basis of the research with the necessary theoretical and practical data, theses, and conceptual definitive elements that allow us to actualize the need to solve the problem mentioned above and come to a unified pedagogical consensus

\section{Results of the research}

Exploring various approaches to the continuous text analysis, it is necessary to highlight the problem field, which served as a pretext for scientific research. In the process of analyzing a text of any kind, we need theoretical and practical training of the student. The need for quick and high-quality analysis without interrupting the educational process has led to the importance of elaborating a strategy for continuous text analysis. 
Hermeneutic text analysis is a researched method for literary criticism. Our task is to elaborate a strategy for its application in the process of teaching philological disciplines.

Hermeneutics in literary criticism is a set of directions and a research method that was developed in the twentieth century, first in the West, and later in Russia and based on the priority of interpretation (revealing different meanings) of a literary text. The hermeneutic analysis of the text becomes universal due to its principles - integrity, emotionality, contextuality, cultural studies, variability, dialogicity. As for the theory, it is of the operations that lead us to the understanding of the texts. And it is that interpreting is reaching a deep understanding of a text. But the notion of text has grown [13]. Of course, it encompasses written texts, but G.G. Gadamer added the spoken text, or the conversation, and P. Ricoeur the meaningful action as a text. It is even known that text can be a painting, a sculpture, a building, etc., which makes us understand G. G. Gadamer's idea of the universality of hermeneutics a little more. In all that man does, he interprets.

The uniqueness of hermeneutic analysis lies in the fact that it can be based on archetypal, general cultural, national and subjective knowledge of the recipient. Hermeneutic analysis is multi-layered and such a research search in this direction can be endless, taking into consideration the inclusion of more monumental sources for the interpretation of the text. Despite this, the primary and continuous analysis of the text in the classroom process can be carried out only by referring to the cultural dictionary of symbols and subjective knowledge.

The task of any such analysis a priori solves the problem of the "hermeneutic circle": the difficulty of transition to the general meaning based on the study of fragments of the text and the reverse movement from the general meaning determined by the researcher to the interpretation of the parts. Due to the hermeneutic analysis, we can search for a detonation when equalizing all connotations and ethically choosing the most relevant of them when analyzing the text directly together with students.

According to V.I. Lykov, such an understanding of hermeneutics allows us to determine its intermediate position between the semiotic approach and the thesaurus approach in philological science. "Hermeneutics was selected as an appropriate research approach since the research goal was to interpret how people understand the construct and practice of judgment artistry. We argue that professional practice entails judgment artistry beyond the simple application of technical knowledge; that judgment artistry in professional practice can be better studied through an interpretive lens compared to an empirical lens; and that hermeneutics is an interpretive approach that is useful for studying judgment artistry of professional practice" [14].

The hermeneutical analysis is one of the most effective methods in the practice of teaching humanities students as such an interpretation work reveals the linguistic, literary and cultural properties of the text. The very hermeneutical approach contributes to effective training of prospective philologists to decode the author's message having its deep-lying roots in the textual space. Such a multilayered message is a unity of hints being dropped by the author and regarded as reference to some universal or cultural background requiring or not reader's philological that is linguoculturological, literary and linguistic competence in identifying the verbalizers and artistic means of embodying cultural symbols evoking in reader's mind the archetypal images, literary devices expressing implicitly the fragment of poetic world picture. The linguistic aspect of the hermeneutical analysis of the text is an integral component of such a methodological strategy $[15,16,17,18,19,20]$.

Based on theoretical and practical knowledge of literary hermeneutics, we can offer a unique strategy for continuous analysis of the text according to this principle:

1. Initial acquaintance. This stage of continuous hermeneutic analysis of the text implies reading the research material for further detailed analysis. 
2. Detection of common cultural image points. Such points can always be decoded and interpreted by an untrained reader.

3. Reconstruction of archetypal images. Such images can draw us to the elements that we are carriers of, regardless of national and cultural affiliation. The analysis of archetypal images draws students to sources close to folklore and mythology, stimulates the application of previously acquired knowledge. The importance of such scientific inclusions in the analysis of the text is determined by the ability to trace transformation processes in images in their genesis. Turning to the problem of archetypes, first of all, it is necessary to emphasize their "overflow" from the mental structure (C. Jung) to the cultural phenomenon, since in the process of modification, the ontological being of archetypes passes from an unconscious archetypal prototype into an actually embodied artistic work. Due to its multidimensional nature, an archetype (or each projection of an archetype has been cut off) can be represented as a text-description, concept, principle, image, geometric, sound or digital symbol, etc. Depending on a particular projection, an archetype can correspond a multitude of outwardly different images embodied in a wide variety of forms, we can say that the archetype as a matrix of culture is a "variability of invariance". Having the ability to change endlessly, nevertheless, the archetype contains an unchanging core that ensures its high stability. Revealing this core (stable basis) is the primary task in the philological analysis of the text.

The analytical task of students is simplified by the fact that archetypes are a pure direction of thinking, a basic level of human mentality, in which the entire experience of natural (pre-cultural) self-organization is filmed in the form of sense-forming directions or pre-conceptual models of structuring.

Despite the different types of archetypes in texts (cultural, ethnocultural and psychological), each of them can be defined without using additional sources during the initial reading. Identification of archetypes and modeling of the schematic image of an archetype includes a number of automatic and conscious operations aimed at activating, activating and activating knowledge about archetypal features embodied in the semantics of the nominative units of the poetic text. This stage presupposes the interpreter's awareness of the theory of archetypes, their classification and content, as well as interpretations of any image as a linguo-cognitive text construct, a three-dimensional quantity that incorporates pre-conceptual, conceptual and verbal hypostases.

4. Detection of national images. In the case of identifying national images, it is necessary to take into consideration the unique figurative color that corresponds to the author's national picture of the world. Despite the direct connection with general cultural and archetypal, national images have a more complex interpretation, which is associated with the difficulty of understanding linguocultural characteristics without involvement in a particular national culture from birth. The most active and primary is always the basic national image, which is reflected in the texts and is called national personification. The national image is a unity of complementary phenomena: national nature, mental make-up and thinking of the people.

5. Detection of author's symbols. These images are basic elements of the text, but they are not correlated with other options, while they are unique in the context of the author's work.

6. Interpretation in order of priority. General cultural images-points are interpreted by students without outside help, they are familiar to them even without the presence of reading and research experience. Other images may require more detailed study, which can be produced using a cultural dictionary of symbols.

7. Carrying out a paradigm between images and their levels in order to collect a complete picture of the artistic world of the text under analysis. 
8. Determination of the linguocultural situation the text is produced in. It is quite evident that modern linguistic and cultural situation may be characterized as a breakdown of social structures, culture, intellectual and spiritual life of society. Thus, the language is in involved in this long-term process. So, the problems of language go beyond philology and join the general spirituality problems of society which are also essentially relevant for today's situation.

Moreover, the study of a language requires an appeal to the factors of an extralinguistic nature that determine its state at the present stage, which leads to the application of a concrete historical approach in the analysis of linguistic phenomena. Today, the influence of sufficiently strong intra-linguistic factors on linguistic processes is carried out in parallel with the powerful influence on them of factors out of the language, i.e. intralingual processes associated with the violation of the systemic laws of the language are under the influence of the changed social speech practice.

It is commonly known that the text is made in a certain period of time and the text interpreter must admit the language functioned at that time. The language of time is considered as a set of linguistic units selected by the authors of texts from a national, constantly evolving language to express thoughts and feelings characteristic of a particular epoch. The combination of the national, group, individual perception of the world represented in the language of a certain time constitutes the essence of linguistic and cultural situation.

9. Revelation of the words and phrases to supply with linguocultural commentary. The compilation of linguocultural commentary is one of the important components of the text analysis because it is a basis for understanding both the external (lexical) features of the text and its internal (cultural) component. Some text fragments require the explanation of some facts referring to language and culture. Such passages reflect national consciousness by means of the language units, verbalize the objects of culture, express valuable cultural categories underlying the components of lexical meanings of the words.

10. Making up a linguocultural vocabulary of the linguistic units expressing a certain aspect of life. At this stage, it is advisable to refer to linguistic and cultural dictionaries, as well as the student's compilation of linguocultural comments, taking into consideration their linguistic and cultural competence. The main task for the teacher in this aspect is to focus on students' understanding not only lexical units, but also, which is especially important, the semantic aspect of the whole text. It also presupposes the identification of language markers and reconstruction of the fragment of semantic space pertaining to certain culture. The author's language resources for encoding the senses are properly selected and even skillfully invented relating to the violation of the language norms and the use of the precedent phenomena representing the cultural values of a nation.

To explain any concept or phenomenon that is difficult for a student's understanding, one should identify this element in the text. Such elements in the texts may be regarded as lexical and semantic gaps. The student focuses on those foreign words which are not recognized as a lexical equivalent and thus constituting the part of the vocabulary of a native language. Such words may be referred to as non-existing words in the native language. In lexical semantics such lexical units are termed lexical gaps.

Perceiving a foreign text, the student follows a set of rules and applies knowledge relevant only to his language and culture. All units interpreted by the student analyzing a foreign text as strange are a specific signal of the presence in the text of linguistic phenomena correlated with the conceptual structure and ethnolinguistic type, identical to the corresponding characteristics of the foreigner. Those concepts or phenomena that in some languages and cultures are designated as generally accepted lexical units expressing the national component, while in others they are not signaled, i.e. do not find a socially fixed expression, are called lexico-semantic lacunae. 
11. Reconstruction of the cultural concept expressed by the linguistic units of the linguocultural vocabulary. Definition of the significance and the way of expressing this cultural concept in other authors' literary works relating to the same or different epochs.

The use of the hermeneutic method in the process of continuous text analysis in the classroom with students stimulates the exploratory search for deep meanings and actualizes scientific research among young scientists. The use of not only ready-made definitions of images from sources, but also the subjective experience of cognition creates a motivational basis for the development of the further skill of continuous text analysis by students outside the classroom.

\section{Conclusions}

The results obtained in the course of this study enabled us to come to a number of conclusions related to the use of the continuous hermeneutical analysis of the text as an important methodological tool for improving the quality of prospective philologists' training. First, the so-called continuous text analysis contributes to the significant improvement the students' level of professional competencies to interpret the text of any genre highlighting its different cultural aspects, as well as encourages their active involvement in the process of acquiring and mastering the field of professional knowledge.

Secondly, the introduction of the continuous text analysis into the process of professional training, students develop their cultural thinking and skills of continuous interpretation of text elements based on interdisciplinary approach, which will find its application in professional activities.

Thirdly, the continuous text analysis is one of the most effective and efficient methodological tools for evaluating students' academic and professional activities, as it enables you to reveal the changes of professional growth and make certain conclusion.

The methodological strategy for the continuous analysis of the text incorporates the step-by-step work. At the first stage of the continuous hermeneutic analysis of the text the students get initial acquaintance with the text under interpretation which implies reading the research material for further detailed analysis of the content and form of the text.

The next methodological step is made to reveal common cultural image points which can always be decoded and interpreted even by an untrained reader. At the third stage the students attempt to reconstruct the archetypal images in the text whether they are psychological or cultural. These ancient images being inherited patterns of thought can be activated in our mind by verbal means used by the author in the text.

The fourth step in continuous text interpretation is to identify national images having the unique figurative color and corresponding to the author's national picture of the world. It is quite obvious for the teacher to introduce the students the tools for the author's symbols explication. Such images are considered as basic elements of the text and unique in the context of the author's work. Dealing with the continuous text analysis the students interpret it in order of priority. General cultural images-points are interpreted by students without outside help. General cultural images are familiar to any student as he or she is a representative of the definite culture and aware of his or her cultural heritage. General cultural images interpretation is possible even if the student does not have reading or research skills. Other types of images may require more detailed study referring to a dictionary of cultural symbols.

At the seventh stage the students attempt to carry out a paradigm between images and their levels in order to reconstruct a complete picture of the artistic world of the text under analysis.

Any text analysis presupposes the identification of the cultural situation the text is produced in. The text may contain the words and phrases having cultural features and the 
students' task is to supply the text analysis with linguocultural commentary of its fragments and then to make up a linguocultural vocabulary expressing a certain aspect of life. The reconstruction of the explicit and implicit information, identification of extra- and intratextual elements are the part of this work.

The last step of textual work is to reconstruct the cultural concept underlying the words and phrases relating to the linguocultural vocabulary. The students are to determine the significance and the verbal means of expressing this cultural concept in other authors' literary works referring to the certain epoch.

Practicing this complex method makes it possible to form and then develop the students' skills of perception and comprehension of texts having cultural significance, to expand the boundaries of understanding the artistic context and intertext. Thus, new methodological tools for text analysis contributes to continuous (multiple) interpretation of the structure and content of the text under consideration.

Grounding on these main points, we believe that the continuous text analysis as the new methodological strategy for the text interpretation in class and independently is effective in terms of improving the overall quality of professional training of students. It is important to understand that the continuous text analysis used in the educational process, interacting with other educational technologies, makes it possible to increase the effects mentioned above and contribute to the process of modernization of the higher professional education system.

\section{References}

1. L.N. Arbachakova, I.A. Nevskaya, Individual linguistic peculiarities of a storyteller (the case of short heroic epic stories' recordings), Tomsk Journal of Linguistics and Anthropology, 3(29), 20-31 (2020)

2. L.L. Aull, Generality and certainty in undergraduate writing over time: a corpus study of epistemic stance across levels, disciplines, and genres, Digitalculturebooks, 5, 139-162 (2019)

3. M. Beuchot, La filosofía de la educación desde una hermenéutica analógico-icónica, Voces de la filosofía de la educación, 21-36 (2017)

4. C. Grandy, Poetics of the record: Robin Coste Lewis's voyage of the Sable Venus, Criticism, 62(4), 519-545 (2020)

5. C.A. Knyazkov, Means of conveying implicit information in lyrics (through the example of the song “We don't wanna put in”, Russian Linguistic Bulletin, 3(23), 48$54(2020)$

6. L.V. Neudacheva, The role of culture in linguistic worldview formation, Russian Linguistic Bulletin, 1(13), 15-17 (2018)

7. V.I. Orekhov, T.R. Orekhova, The role of interactive teaching methods in modern education, Symbol of Science, 6, 242-244 (2015)

8. M.M. Ossola, G. Mancinelli, A. C. Hecht, Educación intercultural bilingüe y formación universitaria: demandas y expectativas de los jóvenes tobas y wichi en argentina, Interculturalidad y educación desde el Sur: Contextos, experiencias y voces, CLACSO, 131-158 (2016)

9. M. Paterson, Using hermeneutics as a qualitative research approach in professional practice, The Qualitative Report, 10(2), 339-357 (2005)

10. J Roth-Gordon, Situating discourse analysis in ethnographic and sociopolitical context, The Cambridge Handbook of Discourse Studies, 32-51 (2021) 
11. A. Shibani, E. Koh, V. Lai, K. J. Shim, Assessing the language of chat for teamwork dialogue, Educational Technology \& Society, 20, 224-237 (2017)

12. R. E. Shkilev. Teaching productive philological reading on the basis of problem search tasks, Modern Journal of Language Teaching Methods, 7(11), 161-170 (2017)

13. J. Szerszunowicz, Lacunarity, lexicography and beyond: integration of the introduction of a linguo-cultural concept and the development of L2 learners' dictionary skills, Lexicography, 2(1), 101-118 (2015)

14. R.L. Troxel, What is the 'text' in textual criticism?, Vetus Testamentum, 66(4), 603626 (2016)

15. C.R. Tulup, Patriotic national identity: theoretical review (on the basis of XIII - XX centuries Scottish poetry), Russian Linguistic Bulletin, 4(24), 166-169 (2020)

16. R. VanDeWeghe, Research matters: expert students, successful intelligence, and wisdom, The English Journal, 94(2), 91-94 (2004)

17. S. Ventura, Digital editing and linguistic analysis: the first redaction of the histoire ancienne jusqu'à César, Textual Cultures, 12(2), 33-56 (2019)

18. A.K. Webster, The poetry of sound and the sound of poetry: Navajo poetry, phonological iconicity, and linguistic relativity, Semiotica, 207, 279-301 (2015)

19. A.K. Webster, (Ethno) Poetics and perspectivism: on the hieroglyphic beauty of ambiguity, Journal of Linguistic Anthropology, 22, 168-174 (2019)

20. T. Wilson-Bates, The image of time in David Copperfield, Dickens Studies Annual, 47, 87-105 (2016) 